\title{
Immunohistochemical detection improves the prognostic value of lymphatic and blood vessel invasion in primary ductal breast cancer
}

\author{
Fadia J A Gujam ${ }^{1,4^{*}}$, James J Going ${ }^{2}$, Zahra M A Mohammed ${ }^{3}$, Clare Orange ${ }^{2}$, Joanne Edwards ${ }^{4}$
} and Donald C McMillan'

\begin{abstract}
Background: Lymphovascular invasion (LBVI) including lymphatic (LVI) and blood (BVI) vessel invasion is a critical step in cancer metastasis. In breast cancer, the optimal detection method of LBVI remains unclear. This research aimed to compare the prognostic value of different assessments of the LVI and BVI in patients with early breast cancer.

Methods: The study cohort included 360 patients with a median follow-up of 168 months. LBVI on H\&E sections $\left(L B V I_{H} \&_{E}\right)$ was reviewed centrally and blinded to the pathology report. Immunohistochemical staining for D2-40 and Factor VIII was performed to identify $L V_{\mathrm{D} 2-40}$ and $B \mathrm{I}_{\mathrm{FV} I I}$.

Results: $L B V I_{H} \&_{E}, L V I_{D 2-40}$ and $B V I_{F V I I I}$ were present in 102 (28\%), 127 (35\%) and 59 (16\%) patients respectively. In node-negative patients (206), LBVI $\&_{\mathrm{E}}, \mathrm{LV} \mathrm{I}_{\mathrm{D} 2-40}$ and $\mathrm{BV} \mathrm{I}_{\mathrm{FV} I I I}$ were present in 41 (20\%), 53 (26\%) and 21 (10\%) respectively. In triple-negative patients (120), $L B V I_{H} \&_{E}, L V I_{D 2-40}$ and $B V I_{F V I I I}$ were present in 35 (29\%), 46 (38\%) and $16(13 \%)$ respectively. $L B V I_{H} \&_{E}$ was significantly associated with tumour recurrence in the whole cohort $(P<0.001)$, node-negative patients $(P=0.001)$ and triple-negative patients $(P=0.004)$. $L V_{D 2-40}$ and $B V I_{F V I I I}$ were significantly associated with tumour recurrence in whole cohort, node-negative (all $P<0.001$ ) and triple-negative patients $(P=0.002)$. In multivariate survival analysis, only $L V_{\mathrm{D} 2-40}$ and $\mathrm{BV} \mathrm{I}_{\mathrm{FV} I I I}$ were independent predictors of cancer specific survival in the whole cohort $(P=0.023$ and $P<0.001$ respectively), node-negative patients $(P=0.004$ and $P=0.001$ respectively) and triple-negative patients ( $P=0.014$ and $P=0.001$ respectively).
\end{abstract}

Conclusion: Assessment of LVI and BVI by IHC using D2-40 and Factor VIII improves prediction of outcome in patients with node-negative and triple-negative breast cancer.

\section{Background}

Breast cancer is a common cancer in female and one of the leading causes of cancer death in women. It accounts for approximately one tenth of all new cancers and a quarter of all female cancer cases [1]. In the UK more than 49,000 women diagnosed with breast cancer in 2011 accounting for $30 \%$ of female cancer incidence. However, the survival rate has improved with $78 \%$ surviving 10 or more years [2].

Lymphovascular invasion (LBVI) including lymphatic (LVI) and blood (BVI) vessel invasion is a critical step in

\footnotetext{
* Correspondence: f.gujam.1@research.gla.ac.uk

'Academic Unit of Surgery, College of Medical, Veterinary and Life

Sciences-University of Glasgow, Royal Infirmary, Glasgow, UK

${ }^{4}$ Wolfson Wohl Cancer Research Centre, Institute of Cancer Sciences, College of Medical, Veterinary and Life Sciences-University of Glasgow, Glasgow, UK Full list of author information is available at the end of the article
}

cancer metastasis. It refers to the invasion of tumour cells into endothelium-lined lymphatic and/or blood vessels $[3,4]$. In breast cancer LBVI has been recognised more than four decades ago [5]. Since then, a number of independent studies have investigated the prognostic value of LBVI in node-negative and node-positive breast cancer [6-17].

The College of American Pathologists (CAP) consensus (1999) and 11th St Gallen meeting (2009) did not agree on the need for specific stains to identify vascular spaces or to distinguish specifically between LVI and BVI $[18,19]$. Although staging guidelines of the American Joint Cancer Committee on Cancer (2005) mandates distinguishing between lymphatic and blood vessel invasion, these guidelines lack a routine standardised and objective assessment method to reliably differentiate them [20]. It remains a challenge to distinguish true LVI and BVI from retraction 
artifacts caused by tissue handling, fixation and processing on haematoxylin and eosin (H\&E) stained sections [21-23].

Numerous studies have reported that LBVI and LVI are powerful prognostic factors of poorer survival in patients with early breast cancer using both $H \& E$ and IHC approaches [24]. While immunohistochemistry (IHC) appears more reliably to detect LBVI and LVI than H\&E, the prognostic role of BVI and optimal detection methods remain unclear [24].

The aim of the present study was to examine the prognostic value of different assessments of LVI and BVI in patients with early, and in particular node-negative and triple-negative breast cancers.

\section{Methods}

Patients

Patients with invasive ductal breast cancer, who had undergone surgery between the years 1995 to 1998 at Royal Infirmary, Western Infirmary, Victoria or Stobhill Hospitals, Glasgow, and had formalin-fixed paraffinembedded blocks of the primary tumour available for evaluation were studied $(n=360)$. Clinicopathological data including age, histological tumour type, grade, tumour size, lymph node status, adjuvant treatment (hormonal therapy and chemotherapy) were retrieved from the routine reports. ER and PR status, using tissue microarrays, were assessed according to the American Society of Clinical Oncology and College of American Pathologists guidelines with cutoff value of $1 \%$ positive tumour nuclei [25]. HER2 status were assessed visually using tissue microarrays as previously described i.e. a score $3+$ is regarded as positive; $2+$ is regarded as equivocal, leading to referral for HER2 FISH; and 0 and $1+$ are regarded as negative [26].

The patients included in this study did not receive neoadjuvant therapy or adjuvant anti-HER-2 therapy. The inclusion of ductal breast cancers only was to limit the potential confounding effects of other tumour types on the analysis in the present study.

Patients were routinely followed up following surgery. Date and cause of death was crosschecked with the cancer registration system and the Registrar General (Scotland). Death records were complete until 31st of May 2013 and that served as the censor date. Cancer recurrence was measured from the date of primary surgery until the date of first recurrence of breast cancer. Cancer specific survival was measured from the date of primary surgery until the date of death from breast cancer.

The Research Ethics Committee of North Glasgow University Hospitals approved the use of human tissue in this study.

\section{Immunohistochemistry}

For visualization of lymphatic and blood vessels, 2 consecutive samples of $2.5 \mu \mathrm{m}$ thick sections from each block (one block/case) were stained for the lymphatic endothelial marker D2-40 (Covance, Monoclonal Antibody, SIG-3730, USA) diluted 1:100 and Factor VIII (Mouse Monoclonal Antibody, NCL-L-Vwf, Leica, Newcastle, UK) diluted 1:100. Sections were dewaxed in xylene and rehydrated through descending concentrations of ethanol. For antigen retrieval of Factor VIII, sections were microwaved for 14 minutes in sodium citrate buffer ( $\mathrm{pH}$ 6). Endogenous hydrogen peroxidase activity was blocked with 3\% $\mathrm{H} 2 \mathrm{O} 2$ for 15 minutes. Non-specific binding was blocked by incubation with $10 \%$ horse serum for 30 minutes. Sections were subsequently incubated with the respective primary antibody; 60 minutes at room temperature for D2-40 and 30 minutes at $25^{\circ} \mathrm{C}$ for Factor VIII. Sites of binding were detected using the Envision technique (Dako, code K5007) with 3-30 diaminobenzidine (Vector, code SK 4001, Burlingame, CA, USA), as chromogenic substrate, according to the manufacturer's instruction. Slides were counterstained with haematoxylin were dehydrated and mounted with DPX. Two full sections of tonsil tissue were used as positive and negative controls for each antibody.

\section{Slide scanning and scoring}

Stained sections with H\&E, D2-40 and Factor VIII were scanned at objective magnification $\times 20$ by Hamamatsu NanoZoomer (Hertfordshire, UK). Assessment of $\mathrm{LBVI}_{\mathrm{H}} \&_{\mathrm{E}}$, $\mathrm{LVI}_{\mathrm{D} 2-40}$ and BVIFactorVIII were carried out on a computer monitor using the Slidepath Tissue IA system version 3.0 (Slidepath, Leica Biosystems).

\section{Assessment of LBVI, LVI and BVI}

LBVI on $\mathrm{H} \& \mathrm{E}$ sections $\left(\mathrm{LBVI}_{\mathrm{H}} \&_{\mathrm{E}}\right.$ ) was reviewed centrally and blinded to the pathology report. For the assessment of $\mathrm{LVI}_{\mathrm{D} 2-40}$ and $\mathrm{BVI}_{\mathrm{FVIII}}$ serial sections, similar to that of $H \& E$ sections, from each block were stained with D2-40 and Factor VIII. $\mathrm{LBVI}_{\mathrm{H}} \&_{\mathrm{E}}, \mathrm{LVI}_{\mathrm{D} 2-40}$ and $\mathrm{BVI}_{\mathrm{FVII}}$ were identified at peritumoural, invasive front or intratumoural areas. $\mathrm{LBVI}_{\mathrm{H}} \&_{\mathrm{E}}$ was identified using criteria previously described [6], as the presence of tumour cell emboli within a vessel space, which were identified by associated fibrin clot and/or an endothelial cell lining. $\mathrm{LVI}_{\mathrm{D} 2-40}$ was identified by tumour cells within D2-40-positively stained vessels, while $\mathrm{BVI}_{\mathrm{FVIII}}$ was counted only when tumour cells were identified in D2-40-negative, Factor VIII-positive vessels. A total of $30 \%$ of $H \& E$ and $I H C$ stained sections for LBVI, LVI and BVI were independently scored by two observers (FJAG, ZMAM) blinded to patient outcome and the other observer's score. The inter class correlation coefficient (ICCC) of $\geq 0.84$ was obtained for $\mathrm{H} \& \mathrm{E}, \mathrm{D} 2-40$ and Factor VIII indicated excellent agreement, and FG scored all the slides and this data was used in the analysis. 


\section{Statistical analysis}

Consistency between the observers was analysed using the ICCC. Interrelationships between variables were assessed using contingency table analysis with $X^{2}$ test for trend as appropriate. Univariate and multivariate survival analysis were performed using the Kaplan-Meier analysis and Cox proportional hazards model with a stepwise backward elimination to derive a final model of variables with a significant independent relationship with survival. All statistical analyses were 2-sided with significance defined as a $P$ value $<0.05$. Deaths up to May 2013 were included in the analysis. All statistical analysis was performed using the SPSS software version 19 (SPSS Inc., Chicago, IL, USA).

\section{Results}

Clinico-pathological characteristics and $\mathrm{LBVI}_{\mathrm{H}} \&_{\mathrm{E}}, \mathrm{LVI}_{\mathrm{D} 2-40}$ and $\mathrm{BVI}_{\mathrm{FVIII}}$ in the whole cohort, in node-negative patients and in triple-negative patients

The clinical and pathological characteristics of the 360 patients are shown in Table 1. Majority of patients were older than 50 years (65\%), had tumours size less than $2 \mathrm{~cm}$ (51\%), had grade III carcinoma (52\%) and no axillary lymph node involvement (57\%). A total of 189 patients (53\%) had ER positive tumours and 166 patients (46\%) had PR positive tumours. Two hundred eighty nine patients (80\%) had HER2 negative tumours with $33 \%$ of patients had triple-negative tumours. 81 patients received endocrine based treatment (22\%) and 144 received chemotherapy (40\%). No information on chemotherapy was available on 7 patients (2\%). Eighty nine patients (24\%) experienced recurrences. Of these patients, 17 (5\%) had local recurrence, 67 (19\%) had distant recurrence and 5 patients had both.

$\mathrm{LBVI}_{\mathrm{H}} \&_{\mathrm{E}}$ was readily identified when tumour cells invaded into large vessels and especially when lymphatic

\begin{tabular}{|c|c|}
\hline Clinico-pathological characteristics & Patients, n (\%) \\
\hline Age $(\leq 50 />50$ years $)$ & $125(35 \%) / 235(65 \%)$ \\
\hline Size $(\leq 20 / 21-50 />50 \mathrm{~mm})$ & $185(51 \%) / 162(45 \%) / 13(4 \%)$ \\
\hline Grade (I / I / III) & 48(13\%)/124(34\%)/188(52\%) \\
\hline Involved lymph node (-ve/+ve) & 206(57\%)/154(43\%) \\
\hline ER status (no/yes) & $171(47 \%) / 189(53 \%)$ \\
\hline PR status (no/yes) & 194(54\%)/166(46\%) \\
\hline HER2 status (no/yes) & 289(80\%)/71(20\%) \\
\hline Triple-negative tumours (no/yes) & $240(67 \%) / 120(33 \%)$ \\
\hline Endocrine therapy (no/yes/unknown) & $272(76 \%) / 81(22 \%) / 7(2 \%)$ \\
\hline Chemotherapy (no/yes/unknown) & $209(58 \%) / 144(40 \%) / 7(2)$ \\
\hline Tumour recurrence (no/local/distant/both) & $271(75 \%) / 17(5 \%) / 67(19 \%) / 5(1 \%)$ \\
\hline Alive/cancer death/non cancer death & 189(53\%)/97(27\%)/74(21\%) \\
\hline
\end{tabular}

vessels were accompanied by adjacent blood vessels, however, invasion into small lymphatic or blood vessels as well as stromal artifact could be difficult to assess (Figure 1). D2-40 stained vessels were usually clear and readily assessed. $\mathrm{LVI}_{\mathrm{D} 2-40}$ was identified by the presence of tumour emboli in vessels that showed D2-40 positivity of the endothelium. Although D2-40 was positive in myoepithelial cells of breast ducts in some cases, this was readily distinguished from lymphatic endothelium by morphological characteristics (Figure 1L).

D2-40 staining was helpful in identifying small lymphatic emboli and lymphatic vessels obscured by tumour cells (Figure 1). Blood vessels were intensely and continuously positive for Factor VIII. Factor VIII staining of lymphatic endothelium was faint or negative (Figure 1). $\mathrm{LVI}_{\mathrm{D} 2-40}$ was generally more extensive than $\mathrm{BVI}_{\mathrm{FVIII}}$ and lymphatic tumour emboli were larger than blood vessel emboli.

$\mathrm{LBVI}_{\mathrm{H}} \&_{\mathrm{E}}$ was reported in $102 / 360$ (28\%) patients, $\mathrm{LVI}_{\mathrm{D} 2-40}$ was present in $127 / 360(35 \%)$ patients and $\mathrm{BVI}_{\mathrm{FVIII}}$ was present in 59/360 (16\%) patients. Eighty nine (25\%) patients had LVI only, whereas twenty one (6\%) patients had BVI only, and thirty eight (10\%) had both LVI and BVI. $\mathrm{LBVI}_{\mathrm{IHC}}\left(\mathrm{LVI}_{\mathrm{D} 2-40}+\mathrm{BVI}_{\mathrm{FVIII}}\right)$ was present in148 (41\%) patients. In node-negative patients (206), $\mathrm{LBVI}_{\mathrm{H}} \&_{\mathrm{E}}$ was present in 41 (20\%), $\mathrm{LVI}_{\mathrm{D} 2-40}$ was present in $53(26 \%)$ and $\mathrm{BVI}_{\mathrm{FVIII}}$ was present in 21 (10\%). In triple-negative patients (120), $\mathrm{LBVI}_{\mathrm{H}} \&_{\mathrm{E}}$ was present in $35(29 \%), \mathrm{LVI}_{\mathrm{D} 2-40}$ was present in $46(38 \%)$ and $\mathrm{BVI}_{\mathrm{FVIII}}$ was present in $16(13 \%)$.

While $\mathrm{LBVI}_{\mathrm{H}} \&_{\mathrm{E}}$ was strongly associated with $\mathrm{LBVI}_{\mathrm{IHC}}$ $(P<0.001), 80(22 \%)$ patients in whom $\mathrm{LBVI}_{\mathrm{H}} \&_{\mathrm{E}}$ had not been identified were positive for $\mathrm{LVI}_{\mathrm{D} 2-40}$ and/or $\mathrm{BVI}_{\mathrm{FVIII}}$. Also, in 34 patients (9\%) in whom $\mathrm{LBVI}_{\mathrm{H}} \&_{\mathrm{E}}$ had been identified, IHC was negative for both $\mathrm{LVI}_{\mathrm{D} 2-40}$ and $\mathrm{BVI}_{\mathrm{FVIII}}$.

As shown in Table 2, the presence of $\mathrm{LBVI}_{\mathrm{H}} \&_{\mathrm{E}}$ was associated with large tumour size $(P<0.001)$, high tumour grade $(P=0.028)$, involved lymph node $(P<0.001)$, and tumour recurrence $(P<0.001)$. No association was seen with hormonal status, HER2 status and endocrine therapy however, there was a trend toward increased chemotherapy (0.067). In node-negative patients, only tumour size $(P=0.008)$ and tumour recurrence $(P=0.001)$ were significantly associated with $\mathrm{LBVI}_{\mathrm{H}} \&_{\mathrm{E}}$. In triple-negative patients, the presence of $\mathrm{LBVI}_{\mathrm{H}} \&_{\mathrm{E}}$ was associated with tumour size $(P=0.025)$, involved lymph node $(P=0.009)$, and tumour recurrence $(P=0.004)$.

Table 3 shows that the presence of $\mathrm{LVI}_{\mathrm{D} 2-40}$ was associated with younger age $(P=0.006)$, large tumour size $(P=0.038)$, high tumour grade $(P<0.001)$, involved lymph node $(P<0.001)$, reduced endocrine therapy $(P=0.014)$, increased chemotherapy $(P=0.002)$ and tumour recurrence $(P<0.001)$. In node-negative patients, the presence of $\mathrm{LVI}_{\mathrm{D} 2-40}$ was associated with younger age $(P=0.008)$ large tumour size $(P=0.019)$ and high tumour grade $(P=0.002)$, HER2 negativity $(P=0.032)$ and tumour recurrence 


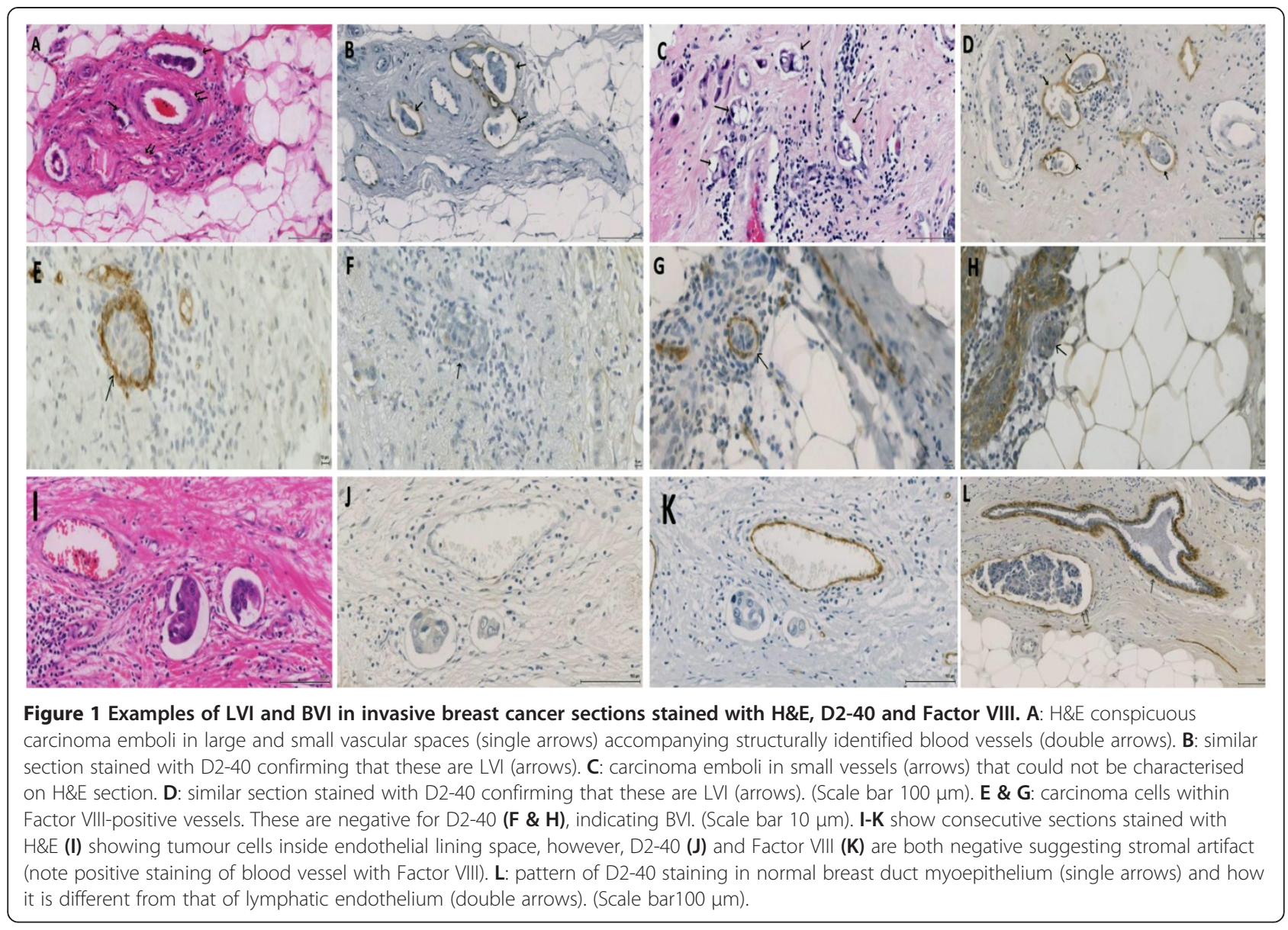

$(P<0.001)$. There was borderline association with reduced endocrine therapy $(P=0.070)$, and increased chemotherapy $(P=0.070)$. In triple-negative patients, the presence of $\mathrm{LVI}_{\mathrm{D} 2-40}$ was associated with involved lymph node $(P=0.001)$ and tumour recurrence $(P<0.001)$.

Table 4 shows that the presence of $\mathrm{BVI}_{\mathrm{FVIII}}$ was associated with large tumour size $(P<0.001)$, high tumour grade $(P=0.044)$, involved lymph node $(P<0.001)$, HER2 negativity $(P=0.003)$ and tumour recurrence $(P<0.001)$. There was no association with hormonal status or treatment received. In node-negative patients, $\mathrm{BVI}_{\mathrm{FVIII}}$ was only significantly associated with larger tumour size $(P=0.002)$ and tumour recurrence $(P<0.001)$. In triple-negative patients, the presence of $\mathrm{BVI}_{\mathrm{FVIII}}$ was significantly associated with tumour size $(P=0.037)$, involved lymph node $(P=0.019)$ and tumour recurrence $(P=0.002)$.

\section{Survival analysis of $\mathrm{LBVI}_{\mathrm{H}} \&_{\mathrm{E}}, \mathrm{LVI}_{\mathrm{D} 2-40}$ and $\mathrm{BVI}_{\mathrm{FVIII}}$ in the whole cohort, in node-negative patients and in triple-negative patients}

The minimum follow-up of survivors was 142 months; median follow-up of survivors was 168 months. During follow up 171 patients died, 97 died of their cancer. The presence of $\mathrm{LBVI}_{\mathrm{H}} \&_{\mathrm{E}}, \mathrm{LVI}_{\mathrm{D} 2-40}$ and $\mathrm{BVI}_{\mathrm{FVIII}}$ were analysed with 15 years follow-up data using the Kaplan-Meier analysis and Cox regression.

Kaplan-Meier curves showed increased risk of death with $\mathrm{LBVI}_{\mathrm{H}} \&_{\mathrm{E}}, \mathrm{LVI}_{\mathrm{D} 2-40}$ and $\mathrm{BVI}_{\mathrm{FVIII}}$ in the whole cohort, node-negative and triple-negative patients (Figure 2). Univariate analysis indicated that $\mathrm{LBVI}_{\mathrm{H}} \&_{\mathrm{E}}$ was significantly associated with cancer specific survival in the whole cohort $(P<0.001)$, node-negative $(P=0.010)$ and in triple-negative patients $(P=0.011)$. The Presence of $\mathrm{LVI}_{\mathrm{D} 2-40}$ was strongly and significantly associated with cancer specific survival in the whole cohort $(P<0.001)$, in node-negative patients $(P=0.001)$ and in triple-negative patients $(P<0.001)$. The presence of $\mathrm{BVI}_{\mathrm{FVIII}}$ was strongly and significantly associated with cancer specific survival in the whole cohort, node-negative and triple-negative patients (all $\mathrm{P}<0.001)$ (Table 5).

In multivariate survival analysis, tumour size $(P=0.014)$, LN status $(P=0.008), \mathrm{LVI}_{\mathrm{D} 2-40}(P=0.023)$ and $\mathrm{BVI}_{\mathrm{FVIII}}$ $(P<0.001)$ remained independently associated with cancer specific survival. In multivariate survival analysis for node-negative patients, tumour size $(P=0.034), \mathrm{LVI}_{\mathrm{D} 2-40}$ $(P=0.004)$ and $\mathrm{BVI}_{\mathrm{FVIII}}(P=0.001)$ remained independent predictors of shorter cancer specific survival. In multivariate survival analysis for triple-negative patients, tumour size 
Table 2 The inter-relationship between clinico-pathological characteristics and lymphovascular invasion $\left(\mathrm{LBV}_{\mathrm{H}} \&_{\mathrm{E}}\right)$ in patients with primary operable invasive ductal breast cancer

\begin{tabular}{|c|c|c|c|}
\hline All patients $(n=360)$ & 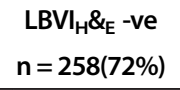 & $\begin{array}{l}\mathrm{LBVI}_{H} \&_{\mathrm{E}}+\mathrm{ve} \\
\mathrm{n}=102(28 \%)\end{array}$ & $(P$-value $)$ \\
\hline Age $(\leq 50 />50$ years $)$ & $86 / 175$ & $39 / 63$ & 0.379 \\
\hline Size $(\leq 20 / 21-50 />50$ mm) & $147 / 106 / 5$ & $38 / 56 / 8$ & $<0.001$ \\
\hline Grade (I / II / III) & $38 / 95 / 125$ & $10 / 29 / 63$ & 0.028 \\
\hline Involved lymph node (-ve/+ve) & $165 / 93$ & $41 / 61$ & $<0.001$ \\
\hline ER status (no/yes) & $119 / 139$ & $52 / 50$ & 0.406 \\
\hline PR status (no/yes) & $137 / 121$ & $57 / 45$ & 0.634 \\
\hline HER2 status (no/yes) & $211 / 47$ & $78 / 24$ & 0.254 \\
\hline $\begin{array}{l}\text { Tumour recurrence } \\
\text { (no/local/distant/both) }\end{array}$ & $213 / 7 / 36 / 2$ & $58 / 10 / 31 / 3$ & $<0.001$ \\
\hline Endocrine therapy (no/yes) & $191 / 63$ & $81 / 18$ & 0.184 \\
\hline Chemotherapy (no/yes) & $158 / 96$ & $51 / 48$ & 0.067 \\
\hline $\begin{array}{l}\text { Alive/cancer death/non } \\
\text { cancer death }\end{array}$ & $148 / 54 / 56$ & $41 / 43 / 18$ & 0.158 \\
\hline $\begin{array}{l}\text { Cancer specific } \\
\text { survival (months) }^{a}\end{array}$ & 178(171-188) & 138(121-155) & $<0.001$ \\
\hline $\begin{array}{l}\text { Node-negative } \\
\text { patients }(n=206)\end{array}$ & $n=165(80 \%)$ & $n=41(20 \%)$ & \\
\hline Age ( $\leq 50 />50$ years $)$ & $51 / 114$ & $16 / 25$ & 0.322 \\
\hline Size $(\leq 20 / 21-50 />50$ mm) & $103 / 60 / 2$ & $17 / 22 / 2$ & 0.008 \\
\hline Grade (I / II / III) & $29 / 60 / 76$ & $5 / 13 / 23$ & 0.233 \\
\hline ER status (no/yes) & $40 / 53$ & $32 / 29$ & 0.252 \\
\hline PR status (no/yes) & $47 / 46$ & $34 / 27$ & 0.529 \\
\hline HER2 status (no/yes) & $138 / 27$ & $30 / 11$ & 0.123 \\
\hline Endocrine therapy (no/yes) & $118 / 46$ & $31 / 9$ & 0.479 \\
\hline Chemotherapy (no/yes) & $113 / 51$ & $29 / 11$ & 0.658 \\
\hline $\begin{array}{l}\text { Tumour recurrence } \\
\text { (no/local/distant/both) }\end{array}$ & $143 / 6 / 15 / 1$ & $27 / 2 / 10 / 2$ & 0.001 \\
\hline $\begin{array}{l}\text { Alive/cancer death/non } \\
\text { cancer death }\end{array}$ & $104 / 23 / 38$ & 20/12/79 & 0.365 \\
\hline $\begin{array}{l}\text { Cancer specific } \\
\text { survival (months) }^{a}\end{array}$ & 190(181-199) & 168(146-190) & 0.010 \\
\hline $\begin{array}{l}\text { Triple-negative } \\
\text { patients }(n=120)\end{array}$ & $n=85(71 \%)$ & $n=35(29 \%)$ & \\
\hline Age ( $\leq 50 />50$ years $)$ & $31 / 54$ & $19 / 16$ & 0.073 \\
\hline Size ( $\leq 20 / 21-50 />50$ mm) & $49 / 34 / 2$ & $14 / 17 / 6$ & 0.025 \\
\hline Grade (I / II / III) & $1 / 14 / 70$ & $0 / 7 / 28$ & 0.888 \\
\hline Involved lymph node (-ve/+ve) & $56 / 29$ & $14 / 21$ & 0.009 \\
\hline $\begin{array}{l}\text { Tumour recurrence } \\
\text { (no/local/distant) }\end{array}$ & $69 / 1 / 15$ & 19/2/14 & 0.004 \\
\hline Endocrine therapy (no/yes) & $76 / 8$ & $31 / 4$ & 0.754 \\
\hline Chemotherapy (no/yes) & $36 / 48$ & $15 / 20$ & 0.999 \\
\hline $\begin{array}{l}\text { Alive/cancer death/non } \\
\text { cancer death }\end{array}$ & $50 / 20 / 15$ & $16 / 17 / 2$ & 0.936 \\
\hline $\begin{array}{l}\text { Cancer specific } \\
\text { survival (months) }^{\text {a }}\end{array}$ & 171(155-187) & 123(96-150) & 0.011 \\
\hline
\end{tabular}

$\mathrm{a}=$ Mean $(95 \% \mathrm{Cl})$
Table 3 The inter-relationship between clinico-pathological characteristics and lymphatic invasion $\left(\mathrm{LV}_{\mathbf{D 2}-40}\right)$ in patients with primary operable invasive ductal breast cancer

\begin{tabular}{|c|c|c|c|}
\hline All patients $(n=360)$ & $\begin{array}{c}\mathrm{LVI}_{\mathrm{D} 2-40-\mathrm{ve}} \\
\mathrm{n}=233 \\
(65 \%)\end{array}$ & $\begin{array}{c}\mathrm{LVI}_{\mathrm{D} 2-40+\mathrm{ve}} \\
\mathrm{n}=127 \\
(35 \%)\end{array}$ & $(P$-value $)$ \\
\hline Age $(\leq 50 />50$ years $)$ & $69 / 164$ & $56 / 71$ & 0.006 \\
\hline Size $(\leq 20 / 21-50 />50$ mm) & $129 / 97 / 7$ & $56 / 65 / 6$ & 0.038 \\
\hline Grade (I / II / III) & $156 / 73 / 13$ & $56 / 53 / 21$ & $<0.001$ \\
\hline Involved lymph node $(0 / 1-3 />3)$ & $153 / 80$ & $53 / 74$ & $<0.001$ \\
\hline ER status (no/yes) & $102 / 131$ & $69 / 58$ & 0.056 \\
\hline PR status (no/yes) & $118 / 115$ & $76 / 51$ & 0.095 \\
\hline HER2 status (no/yes) & $193 / 40$ & $96 / 31$ & 0.099 \\
\hline Endocrine therapy (no/yes) & $168 / 62$ & $104 / 19$ & 0.014 \\
\hline Chemotherapy (no/yes) & $150 / 80$ & $59 / 64$ & 0.002 \\
\hline $\begin{array}{l}\text { Tumour recurrence } \\
\text { (no/local/distant/both) }\end{array}$ & 199/5/28/1 & $72 / 12 / 39 / 4$ & $<0.001$ \\
\hline $\begin{array}{l}\text { Alive/cancer death/non } \\
\text { cancer death }\end{array}$ & $141 / 39 / 53$ & $48 / 58 / 21$ & 0.059 \\
\hline Cancer specific survival (months) ${ }^{a}$ & 186(177-194) & 134(120-149) & $<0.001$ \\
\hline
\end{tabular}

Node-negative disease $(n=206) \quad n=153(74 \%) \quad n=53(26 \%)$

Age ( $\leq 50 />50$ years)

$\begin{array}{lll}42 / 111 & 25 / 28 & 0.008\end{array}$

Size $(\leq 20 / 21-50 />50 \mathrm{~mm})$

96/55/2 24/27/2

0.019

Grade (I / II / III)

$\begin{array}{lll}33 / 53 / 67 & 1 / 20 / 32 & 0.002\end{array}$

ER status (no/yes)

$32 / 48$

$40 / 34$

0.082

PR status (no/yes)

HER2 status (no/yes)

$38 / 42$

$43 / 31$

0.189

Endocrine therapy (no/yes)

$130 / 23$

$38 / 15$

0.032

$106 / 46$

$43 / 9$

0.070

Chemotherapy (no/yes)

$111 / 41$

$31 / 21$

0.070

Tumour recurrence

(no/local/distant/both)

$137 / 4 / 11 / 1 \quad 33 / 4 / 14 / 2 \quad<0.001$

Alive/cancer death/non

$99 / 18 / 36 \quad 25 / 17 / 11 \quad 0.266$

cancer death

Cancer specific survival (months) ${ }^{\mathrm{a}}$

198(190-206)

153(131-174)

0.001

Triple-negative patients $(n=120)$

$n=74(62 \%)$

$46(38 \%)$

Age $(\leq 50 />50$ years)

$26 / 48$

24/22

0.064

Size $(\leq 20 / 21-50 />50 \mathrm{~mm})$

$42 / 28 / 4$

$21 / 23 / 2$

0.367

Grade (I / II / III)

$1 / 13 / 60$

$0 / 8 / 38$

0.712

Involved lymph node (-ve/+ve)

$52 / 22$

$18 / 28$

0.001

Endocrine therapy (no/yes)

Chemotherapy (no/yes)

$65 / 9$

$42 / 3$

0.336

$36 / 38$

$15 / 30$

0.103

Tumour recurrence

$64 / 0 / 10$

$24 / 3 / 19$

$<0.001$

(no/local/distant)

Alive/cancer death/non

$48 / 13 / 13$

$18 / 24 / 4$

0.217

Cancer specific survival (months) $^{a} \quad$ 176(161-192) $\quad$ 122(96-147) $\quad<0.001$ 
Table 4 The inter-relationship between clinico-pathological characteristics and blood vessel invasion $\left(\mathrm{BVI}_{\mathrm{FVIII}}\right)$ in patients with primary operable invasive ductal breast cancer

\begin{tabular}{|c|c|c|c|}
\hline All patients $(n=360)$ & $\begin{array}{c}\mathrm{BVI}_{\mathrm{FVIII}}-\mathrm{ve} \\
\mathrm{n}=301 \\
(84 \%)\end{array}$ & $\begin{array}{c}\mathrm{BVI}_{\mathrm{FVIII}}+\mathrm{ve} \\
\mathrm{n}=59 \\
(16 \%)\end{array}$ & ( $P$-value) \\
\hline Age $(\leq 50 />50$ years $)$ & 104/197 & $21 / 38$ & 0.848 \\
\hline Size $(\leq 20 / 21-50 />50 \mathrm{~mm})$ & $168 / 123 / 10$ & $17 / 39 / 3$ & $<0.001$ \\
\hline Grade (I / II / III) & $45 / 104 / 152$ & $3 / 20 / 36$ & 0.044 \\
\hline Involved lymph node (-ve/+ve) & $185 / 116$ & $21 / 38$ & $<0.001$ \\
\hline ER status (no/yes) & 139/162 & $32 / 27$ & 0.258 \\
\hline PR status (no/yes) & $158 / 143$ & $36 / 23$ & 0.230 \\
\hline HER2 status (no/yes) & $250 / 51$ & $39 / 20$ & 0.003 \\
\hline Endocrine therapy (no/yes) & $226 / 70$ & $46 / 11$ & 0.475 \\
\hline Chemotherapy (no/yes) & $178 / 118$ & $31 / 26$ & 0.419 \\
\hline $\begin{array}{l}\text { Tumour recurrence } \\
\text { (no/local/distant/both) }\end{array}$ & $243 / 13 / 42 / 3$ & $28 / 4 / 25 / 2$ & $<0.001$ \\
\hline $\begin{array}{l}\text { Alive/cancer death/non } \\
\text { cancer death }\end{array}$ & $179 / 60 / 62$ & $10 / 37 / 12$ & $<0.001$ \\
\hline Cancer specific survival (months) ${ }^{a}$ & 181(173-189) & $93(73-112)$ & $<0.001$ \\
\hline Node-negative disease $(n=212)$ & $n=185(90 \%)$ & $\mathrm{n}=21(10 \%)$ & \\
\hline Age $(\leq 50 />50$ years $)$ & $58 / 132$ & $10 / 12$ & 0.157 \\
\hline Size $(\leq 20 / 21-50 />50 \mathrm{~mm})$ & $118 / 69 / 3$ & $6 / 15 / 1$ & 0.002 \\
\hline Grade (I / II / III) & $36 / 66 / 88$ & $1 / 9 / 12$ & 0.180 \\
\hline ER status (no/yes) & $50 / 66$ & $22 / 16$ & 0.114 \\
\hline PR status (no/yes) & $58 / 58$ & $23 / 15$ & 0.261 \\
\hline HER2 status (no/yes) & $158 / 32$ & $16 / 6$ & 0.228 \\
\hline Endocrine therapy (no/yes) & $133 / 50$ & $16 / 5$ & 0.732 \\
\hline Chemotherapy (no/yes) & $129 / 54$ & $13 / 8$ & 0.419 \\
\hline $\begin{array}{l}\text { Tumour recurrence } \\
\text { (no/local/distant/both) }\end{array}$ & $163 / 9 / 15 / 3$ & $12 / 0 / 10 / 0$ & $<0.001$ \\
\hline $\begin{array}{l}\text { Alive/cancer death/non } \\
\text { cancer death }\end{array}$ & $125 / 24 / 41$ & $3 / 11 / 8$ & 0.001 \\
\hline Cancer specific survival (months) ${ }^{a}$ & 194(186-202) & 110(75-146) & $<0.001$ \\
\hline Triple-negative patients $(n=120)$ & $n=104(87 \%)$ & $n=16(13 \%)$ & \\
\hline Age $(\leq 50 />50$ years $)$ & $44 / 60$ & $6 / 10$ & 0.718 \\
\hline Size $(\leq 20 / 21-50 />50 \mathrm{~mm})$ & $59 / 40 / 5$ & $4 / 11 / 1$ & 0.037 \\
\hline Grade (I / II / III) & $1 / 16 / 87$ & $0 / 5 / 11$ & 0.212 \\
\hline Involved lymph node (-ve/+ve) & $65 / 39$ & $5 / 11$ & 0.019 \\
\hline Endocrine therapy (no/yes) & $92 / 12$ & $15 / 0$ & 0.167 \\
\hline Chemotherapy (no/yes) & $45 / 59$ & $6 / 9$ & 0.812 \\
\hline $\begin{array}{l}\text { Tumour recurrence } \\
\text { (no/local/distant) }\end{array}$ & $81 / 3 / 20$ & $7 / 0 / 9$ & 0.002 \\
\hline $\begin{array}{l}\text { Alive/cancer death/non } \\
\text { cancer death }\end{array}$ & $64 / 24 / 16$ & $2 / 13 / 1$ & 0.014 \\
\hline Cancer specific survival (months) ${ }^{a}$ & 172(157-186) & $64(37-92)$ & $<0.001$ \\
\hline
\end{tabular}

$\mathrm{a}=$ Mean $(95 \% \mathrm{Cl})$
$(P<0.001), \mathrm{LN}$ status $(P=0.008), \mathrm{LVI}_{\mathrm{D} 2-40}(P=0.014)$ and $\mathrm{BVI}_{\mathrm{FVIII}}(P=0.001)$ remained independently associated with cancer specific survival (Table 5).

\section{Discussion}

The results of the present study show that $\mathrm{LBVI}_{\mathrm{H}} \&_{\mathrm{E}}$, $\mathrm{LVI}_{\mathrm{D} 2-40}$ and $\mathrm{BVI}_{\mathrm{FVIII}}$ all predicted tumour recurrence and cancer specific survival in an observational cohort of patients with early breast cancer. These results make a case for routine clinical assessment of lymphatic and blood vessel invasion by IHC to ascertain LVI and BVI.

In the present study, the proportion of patients with $\mathrm{LBVI}_{\mathrm{H}} \&_{\mathrm{E}}(28 \%)$ was consistent with most previous studies of breast cancer compared with (22-48\%) in the literature, (20\%) compared with (15-28\%) for patients with nodenegative tumour, and (29\%) compared with (24-45\%) for patients with triple-negative tumour [24]. Similarly, in terms of the association between $\mathrm{LBVI}_{\mathrm{H}} \&_{\mathrm{E}}$ and other well established high risk features such as tumour size, LN status, tumour grade, and breast cancer recurrence and survival are consistent with previous studies. Therefore, the present cohort is consistent with previous reports in which the prognostic value of $\mathrm{LBVI}_{\mathrm{H}} \&_{\mathrm{E}}$ has been established.

In the present study, the proportion of patients with $\mathrm{LVI}_{\mathrm{D} 2-40}(35 \%)$ was consistent with most previous studies using a similar approach (28-46\%), (26\%) compared with (15-28\%) for patients with node-negative tumour, and (38\%) compared with (26-41\%) for patients with triplenegative tumour [24]. $\mathrm{LVI}_{\mathrm{D} 2-40}$ was associated with other well established high risk features such as tumour size, LN status, tumour grade, and with tumour recurrence. In addition, the presence of $\mathrm{LVI}_{\mathrm{D} 2-40}$ was significantly associated with reduced hormonal treatment and increased chemotherapy.

Furthermore, the presence of $\mathrm{LVI}_{\mathrm{D} 2-40}$ provided independent prognostic information not only in the whole cohort but also in the subgroup of patients with lymph node-negative and triple-negative breast cancer. These results are consistent with recent studies that assessed LVI objectively using D2-40 $[16,17,27,28]$. Thus, the present study confirms that D2-40 staining is a practical and effective way of identifying endothelial cells lining lymphatic vessels in patients with early breast cancer, in particular node-negative disease. These findings suggest that $\mathrm{LVI}_{\mathrm{D} 2-40}$ might usefully be incorporated into the routine clinical pathological staging of patients with breast cancer.

In the present study, the proportion of patients with BVI (Factor VIII) was lower than that of previous studies by Kato and colleagues that used a similar approach (16\%) compared to (27-29\%) in the whole cohort and (10\%) compared to (18\%) in node-negative patients $[15,29,30]$. Given that Kato and colleagues did not use a specific lymphatic marker such as D2-40 to differentiate between lymphatic and blood vessels and that Factor VIII has been found to be 


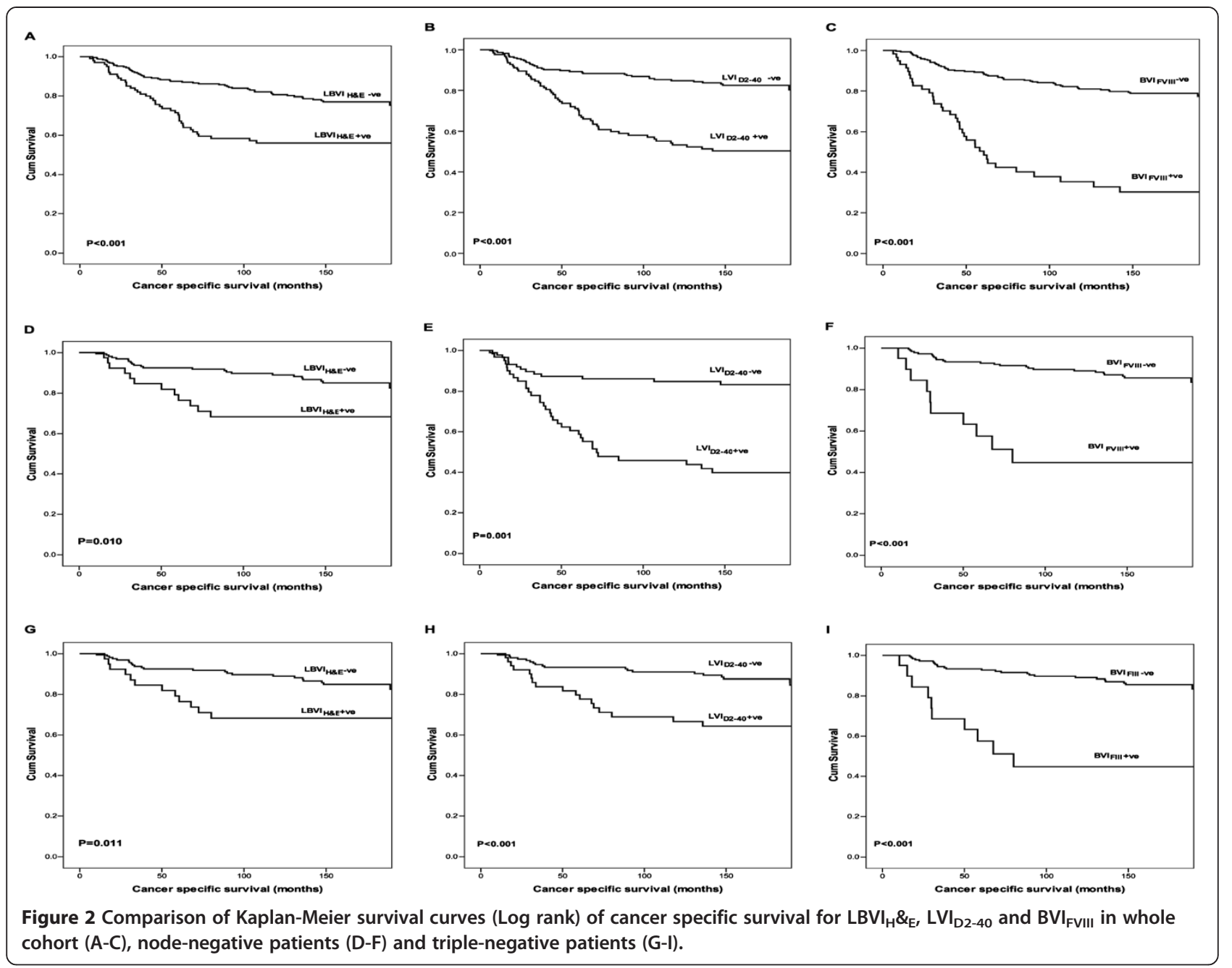

occasionally reactive to lymphatic endothelium, it may be that the higher rate reported by Kato and co-workers reflects LVI being assessed as BVI. Moreover, the present cohort would not explain the large discrepancy between the present BVI rate and that reported by Mohammed and colleagues [16,17] of only $0.7 \%$ of cases. Clearly, further prospective work is required across multiple centres to standardise the reporting of BVI, an important determinant of outcome in primary operable ductal breast cancer.

The results of the present study show for the first time the significance of BVI in triple-negative breast cancer. This is an important finding, because currently used clinic-opathologic and molecular markers, including the recent multigene assays, have a limited prognostic value in this molecular subtype. Most of these tumours are of high grade and exhibit poor prognosis gene signatures [31-33]. Thus objective assessment of BVI may provide additional independent prognostic information for this clinically important subgroup, in whom risk stratification and decisions about systemic therapy need to be determined.
The results of the present study suggest that BVI is less frequent than LVI in breast cancer, consistent with previous studies $[15,22,34,35]$. This would suggest that LVI is potentially a more important route of breast cancer spread. However, results of the present study show that twenty one of 212 patients (10\%) without lymph node metastases had BVI. Blood vessel invasion in patients without lymph node metastases may explain the subsequent development of metastatic disease.

It is recognised that D2-40 may stain myoepithelial cells of the normal breast ducts and ductal carcinoma in situ (DCIS) especially in small ducts completely filled by solid-pattern DCIS [36-38]. There is evidence that p63 staining may be useful in distinguishing D2-40 positive myoepithelium. However, this would increase the complexity of the present approach for routine clinical pathological analysis. Moreover, with awareness that myoepithelium may also be immunoreactive largely obviates this problem. Specifically, the tumour growth pattern enables distinction of ductal carcinoma in situ from lymphovascular invasion. Also, the myoepithelium is discontinuous in small ducts 
Table 5 The relationship between clinic-pathological characteristics and cancer specific survival in patients with primary operable invasive ductal breast cancer

\begin{tabular}{|c|c|c|c|c|}
\hline \multirow[t]{2}{*}{ All patients $(n=360)$} & \multicolumn{2}{|c|}{ Univariate analysis } & \multicolumn{2}{|c|}{ Multivariate analysis } \\
\hline & Hazard ratio $(95 \% \mathrm{Cl})$ & $P$-value & Hazard ratio $(95 \% \mathrm{Cl})$ & $P$-value \\
\hline Age $(\leq 50 />50$ years $)$ & $0.97(0.64-1.45)$ & 0.861 & & \\
\hline Size $(\leq 20 / 21-50 />50 \mathrm{~mm})$ & $2.16(1.52-3.05)$ & $<0.001$ & $1.58(1.09-2.29)$ & 0.014 \\
\hline Grade (I / II / III) & $1.84(1.31-2.57)$ & $<0.001$ & $1.43(1.00-2.05)$ & 0.049 \\
\hline Involved lymph node (-ve/+ve) & $2.83(1.87-4.28)$ & $<0.001$ & $1.82(1.17-2.83)$ & 0.008 \\
\hline ER (no/yes) & $0.59(0.39-0.89)$ & 0.012 & & 0.571 \\
\hline PR (no/yes) & $0.72(0.48-1.09)$ & 0.128 & & \\
\hline HER2 status (no/yes) & $1.34(0.84-2.14)$ & 0.216 & & \\
\hline Endocrine therapy (no/yes) & $0.48(0.26-0.88)$ & 0.018 & & 0.114 \\
\hline Chemotherapy (no/yes) & $1.56(1.05-2.33)$ & 0.029 & & 0.611 \\
\hline LBV| $\left.\right|_{H} \&_{E}$ (absent/present) & $2.39(1.61-3.54)$ & $<0.001$ & & 0.196 \\
\hline $\mathrm{LVI}_{\mathrm{D} 2-40}$ (absent/present) & $3.31(2.19-4.97)$ & $<0.001$ & $1.69(1.08-2.67)$ & 0.023 \\
\hline$B V I_{F V I I I}($ absent/present) & $5.12(3.38-7.78)$ & $<0.001$ & $3.35(2.21-5.63)$ & $<0.001$ \\
\hline \multicolumn{5}{|l|}{ Node-negative patients $(n=212)$} \\
\hline age $(\leq 50 />50$ years $)$ & $0.69(0.36-1.36)$ & 0.290 & & \\
\hline Size $(\leq 20 / 21-50 />50 \mathrm{~mm})$ & $2.33(2.32-3.31)$ & 0.007 & $1.93(1.04-3.59)$ & 0.038 \\
\hline Grade (I / II / III) & $1.64(1.64-2.74)$ & 0.061 & & 0.184 \\
\hline ER (no/yes) & $0.75(0.38-1.45)$ & 0.388 & & \\
\hline PR (no/yes) & $0.91(0.47-1.78)$ & 0.780 & & \\
\hline HER2 status (no/yes) & $2.11(1.03-4.31)$ & 0.040 & & 0.368 \\
\hline Endocrine therapy (no/yes) & $0.91(0.41-2.02)$ & 0.822 & & \\
\hline Chemotherapy (no/yes) & $0.83(0.39-1.72)$ & 0.612 & & \\
\hline LBV| $\left.\right|_{H} \&_{E}$ (absent/present) & $2.43(1.21-4.89)$ & 0.010 & & 0.649 \\
\hline $\mathrm{LVI}_{\mathrm{D} 2-40}$ (absent/present) & $3.24(1.67-6.29)$ & 0.001 & $2.29(1.15-4.58)$ & 0.004 \\
\hline BVI $I_{F V I I I}$ (absent/present) & $6.03(2.87-13.77)$ & $<0.001$ & $4.43(2.07-9.51)$ & 0.001 \\
\hline \multicolumn{5}{|l|}{ Triple-negative patients $(n=120)$} \\
\hline age $(<50 />50$ years $)$ & $1.09(0.57-2.01)$ & 0.784 & & \\
\hline Size $(\leq 20 / 21-50 />50 \mathrm{~mm})$ & $3.43(2.01-5.85)$ & $<0.001$ & $2.94(1.65-5.24)$ & $<0.001$ \\
\hline Grade (I / II / II) & $0.79(0.39-1.58)$ & 0.503 & & \\
\hline Involved lymph node (-ve/+ve) & $4.08(2.01-8.27)$ & $<0.001$ & $2.36(1.11-5.03)$ & 0.026 \\
\hline Endocrine therapy (no/yes) & $0.89(0.27-2.89)$ & 0.842 & & \\
\hline Chemotherapy (no/yes) & $0.93(0.48-1.78)$ & 0.824 & & \\
\hline LBV| ${ }_{H} \&_{E}$ (absent/present) & $2.31(1.21-4.42)$ & 0.011 & & 0.294 \\
\hline $\mathrm{LVI}_{\mathrm{D} 2-40}$ (absent/present) & $3.57(1.82-7.04)$ & $<0.001$ & $2.61(1.36-5.04)$ & 0.014 \\
\hline$B V_{\mathrm{FVIII}}$ (absent/present) & 4.68(3.09-10.31) & $<0.001$ & $3.63(1.38-6.56)$ & 0.001 \\
\hline
\end{tabular}

whereas the endothelial lining of the lymph vessels is continuous and the myoepithelial cells of larger ducts are larger than the endothelial cells of lymph vessels [39]. Finally, the distribution of the stain for the myoepithelial cells is recognised to be patchy and the intensity less than that of the adjacent lymphatic endothelium [40]. Therefore, increase in sensitivity of detection of lymph vessel invasion may be reasonably attributed to the demarcation of lymphatic endothelium that stains positively for D2-40 around the tumour emboli and although, D2-40 may also bind to myoepithelium of breast ducts, it is not difficult to distinguish between myoepithelial reactivity and endothelial staining of the vessels.

Factor VIII has been previously reported as a blood vessel endothelial marker in breast cancer and is consistently found in normal endothelial cells in blood vessels. While it occasionally stains endothelial cells in lymphatics, staining of lymphatic endothelium is usually 
faint and discontinuous [21,29,41]. Some studies have suggested that the vascular marker CD31 may be superior to factor VIII for blood vessels staining $[42,43]$. However, another study reported that the higher sensitivity of CD31 of vascular endothelium did not yield results more discriminating for predicting survival outcome than results produced with factor VIII [44].

In the present study, although the value of lymphovascular invasion detected using IHC was significantly correlated with the value of lymphovascular invasion detected using H\&E $(P<0.001), 80(22 \%)$ patients that were negative for lymphovascular invasion on $\mathrm{H} \& \mathrm{E}$ showed positive $\mathrm{LVI}_{\mathrm{D} 2-40}$ and/or $\mathrm{BVI}_{\mathrm{FVIII}}$, indicating that the frequency of detection of lymphovascular invasion increased using IHC. These lesions were difficult to identify on the H\&E sections due to invasion into small lymphatic or blood vessels or due to vessels that had been obscured by tumour cells. Thirty four patients had tumours that were $\mathrm{LBVI}_{\mathrm{H}} \&_{\mathrm{E}}$ positive, were negative for both $\mathrm{LVI}_{\mathrm{D} 2-40}$ and $\mathrm{BVI}_{\mathrm{FVIII}}$. A recognised explanation for such a discrepancy is that stromal retraction artifacts, caused by tissue handling and fixation, on H\&E sections cause false positives [7,21-23]. In addition, the H\&E approach has considerable interobserver variability and lower overall detection rate in most previous studies [24]. The significance of this is that although AJCC guidelines mandate the reporting of lymphatic and blood vessel invasion, they lack a routine standardized pathological methodology to reliably report them.

The results of the present and previous studies [24] point to a substantial improvement in the consistency of reporting and an increase in the rate of detection of LBVI, LVI and BVI in patients with breast cancer cases using an IHC approach. Such an improvement has been documented with lymphatic (eg, podoplanin/D2-40) and blood vessel (eg, CD34 and CD31) endothelial markers. Moreover, these markers not only discriminate retraction artifacts from LVI and BVI but also distinguish between lymph vessels and blood vessels, allowing specifically study of LVI and BVI $[7,16,21,36,39]$.

A limitation of the present study was that intra- and peritumoral LBVI foci were not separately analysed owing to small number of cases with intratumoural $\mathrm{LBVI}_{\mathrm{H}} \&_{\mathrm{E}}$ (5\%) compared to the $(95 \%)$ of peritumoural $\mathrm{LBVI}_{\mathrm{H}} \&_{\mathrm{E}}$. This precluded meaningful analysis of each component but was unlikely to materially influence the concordance between the detection of LBVI-H\&E and LBVI-IHC. Although, several previous studies have reported the prognostic significance of LBVI using H\&E staining these studies have not discriminated between the types of vessel invasion whether lymphatic or blood vessel and have inconsistently used the terms vascular or lymphovascular invasion. For example, the American Joint Committee on Cancer (AJCC) staging guidelines (2005) has used the term lymphovascular invasion to indicate both lymphatic and vascular involvement [20]. This clearly may be confusing as these terms may indicate involvement of lymphatic or lymphatic and blood vessels. This is largely a pragmatic approach to the limitations of the routine use of H\&E slides to assess lymphovascular invasion. Another limitation was that the well established factors such as grade and ER status were not independently associated with cancer specific survival in all patients and in those with node-negative or triple-negative disease. This may suggest that the sample size was rather small for such multivariate analysis. Nevertheless, the results are of interest and make a case for further studies of routine clinical assessment of lymphatic and blood vessel invasion by IHC to ascertain LVI and BVI.

\section{Conclusions}

In summary, the results of the present study show that IHC for D2-40 and Factor VIII define lymphatic and blood vessel invasion with greater sensitivity and specificity than H\&E, improving detection of LVI and BVI in early invasive breast cancer. Moreover, the prognostic significance of the $\mathrm{LVI}_{\mathrm{D} 2-40}$ and $\mathrm{BVI}_{\mathrm{FVIII}}$ was superior to that of $\mathrm{LBVI}_{\mathrm{H}} \&_{\mathrm{E}}$ and this was consistent throughout analysis of sub-cohorts. Therefore, these results make the case for their assessment in routine clinic-pathological practice.

\section{Competing interests}

The authors declare that they have no competing interest.

\section{Authors' contributions}

Conception and design: FJAG, DCMCM and JG. Development of methodology: FJAG, JG and JE. Acquisition of data: FJAG, JE, ZMAM and CO. Analysis and interpretation of data: FJAG and DCMCM. Writing, review and/or revision of the manuscript: all co-author. Administrative, technical, or material support: JG, JE and CO. Study supervision: DCMCM. All authors read and approved the final version of the manuscript.

\section{Acknowledgements}

The authors gratefully acknowledge funding from Libyan government-Ministry of Higher Education.

\section{Author details}

${ }^{1}$ Academic Unit of Surgery, College of Medical, Veterinary and Life Sciences-University of Glasgow, Royal Infirmary, Glasgow, UK. ²University Section of Pathology, College of Medical, Veterinary and Life

Sciences-University of Glasgow, Southern General Hospital, Glasgow, UK. ${ }^{3}$ University Departments of Pathology, Faculty of Veterinary Medicine, Omar Almukhtar University, Al bayda, Libya. ${ }^{4}$ Wolfson Wohl Cancer Research Centre, Institute of Cancer Sciences, College of Medical, Veterinary and Life Sciences-University of Glasgow, Glasgow, UK.

Received: 6 October 2013 Accepted: 16 September 2014 Published: 18 September 2014

\section{References}

1. Ferlay J, Parkin D, Steliarova-Foucher E: Estimates of cancer incidence and mortality in Europe in 2008. Eur J Cancer 2010, 46:765-781.

2. Cancerstats: Breast Cancer Statistics. http://www.cancerresearchuk.org/ cancer-info/cancerstats/types/breast/. Accessed May 2013.

3. Rosai J, Sobin L: Tumors of the Mammary Gland. Washington: DC: Armed Forces Institute of Pathology; 1993.

4. Gilchrist KW, Gould VE, Hirschl S, Imbriglia JE, Patchefsky AS, Penner DW Pickren J, Schwartz IS, Wheeler JE, Barnes JM, Mansour EG: Interobserver variation in the identification of breast-carcinoma in intra-mammary lymphatics. Hum Pathol 1982, 13:170-172. 
5. Teel P: Vascular invasion as a prognostic factor in breast carcinoma. Surg Gynecol Obstetrics 1964, 118:1006-1008.

6. Davis BW, Gelber R, Goldhirsch A, Hartmann WH, Hollaway L, Russell I, Rudenstam CM: Prognostic significance of peritumoral vessel invasion in clinical trials of adjuvant therapy for breast cancer with axillary lymph node metastasis. Hum Pathol 1985, 16:1212-1218.

7. Bettelheim R, Mitchell D, Gusterson BA: Immunocytochemistry in the identification of vascular invasion in breast-cancer. J Clin Pathol 1984, 37:364-366.

8. Pinder SE, Ellis IO, Galea M, Orourke S, Blamey RW, Elston CW: Pathological prognostic factors in breast-cancer.III. Vascular invasion - relationship with recurrence and survival in a large study with long-term follow-up. Histopathology 1994, 24:41-47.

9. de Mascarel I, Bonichon F, Durand M, Mauriac LH, Macgrogan G, Soubeyran I, Picot V, Avril A, Coindre JM, Trojani M: Obvious peritumoral emboli: an elusive prognostic factor reappraised. Multivariate analysis of 1320 node-negative breast cancers. Eur J Cancer 1998, 34:58-65.

10. McCready DR, Chapman JAW, Hanna WM, Kahn HJ, Murray D, Fish EB, Trudeau ME, Andrulis IL, Lickley LA: Factors affecting distant disease-free survival for primary invasive breast cancer: use of a log-normal survival model. Ann Surg Oncol 2000, 7:416-426.

11. Lee AHS, Pinder SE, Macmillan RD, Mitchell M, Ellis IO, Elston CW, Blamey RW: Prognostic value of lymphovascular invasion in women with lymph node negative invasive breast carcinoma. Eur J Cancer 2006, 42:357-362.

12. Viale G, Rotmensz N, Maisonneuve P, Bottiglieri L, Montagna E, Luini A, Veronesi P, Intra M, Torrisi R, Cardillo A, Campagnoli E, Goldhirsch A, Colleoni M: Invasive ductal carcinoma of the breast with the "triple-negative" phenotype: prognostic implications of EGFR immunoreactivity. Breast Cancer Res Treat 2009, 116:317-328.

13. Ejlertsen $B$, Jensen MB, Rank F, Rasmussen BB, Christiansen P, Kroman N, Kvistgaard ME, Overgaard M, Toftdahl DB, Mouridsen HT, on behalf of the Danish Breast Cancer Cooperative Group: Population-based study of peritumoral lymphovascular invasion and outcome among patients with operable breast cancer. J Natl Cancer Inst 2009, 101:729-735.

14. Ragage F, Debled M, MacGrogan G, Brouste V, Desrousseaux M, Soubeyran I, de Lara CT, Muriac L, de Mascarel I: Is it useful to detect lymphovascular invasion in lymph node-positive patients with primary operable breast cancer? Cancer 2010, 116:3093-3101.

15. Kato T, Kameoka S, Kimura T, Nishikawa T, Kobayashi M: The combination of angiogenesis and blood vessel invasion as a prognostic indicator in primary breast cancer. Br J Cancer 2003, 88:1900-1908.

16. Mohammed RA, Martin SG, Gill MS, Green AR, Paish EC, Ellis IO: Improved methods of detection of lymphovascular invasion demonstrate that it is the predominant method of vascular invasion in breast cancer and has important clinical consequences. Am J Surg Pathol 2007, 31:1825-1833.

17. Mohammed RA, Martin SG, Mahmmod AM, Green AR, Paish EC, Ellis IO: Objective assessment of lymphatic and blood vascular invasion in lymph node-negative breast carcinoma: findings from a large case series with long-term follow-up. J Pathol 2011, 223:358-365.

18. Fitzgibbons PL, Page DL, Weaver D, Thor AD, Allred DC, Clark GM, Ruby SG O'Malley F, Simpson JF, Connolly JL, Hayes DF, Edge SE, Lichter A, Schnitt SJ: Prognostic factors in breast cancer. College of American pathologists consensus statement 1999. Archives Pathol Lab Med 2000, 124:966-978.

19. Goldhirsch A, Ingle JN, Gelber RD, Coates AS, Thurlimann T, Senn HJ: Thresholds for therapies: highlights of the St Gallen international expert consensus on the primary therapy of early breast cancer. Ann Oncol 2009, 20:1319-1329.

20. Wittekind C, Hutter R, Grenee FL, Klimpfinger M, Sobin LH: TNM Atlas: Illustrated Guideline to the TNM Classification of Malignant Tuomurs. New York: Wiley; 2005.

21. Saigo PE, Rosen PP: The application of immunohistochemical stains to identify endothelial-lined channels in mammary carcinoma. Cancer 1987, 59:51-54.

22. Van den Eynden G, Van der Auwera I, Van Laere S, Colpaert C, van Dam P, Dirix L, Vermeulen P, Van Marck E: Distinguishing blood and lymph vessel invasion in breast cancer: a prospective immunohistochemical study. Br J Cancer 2006, 94:1643-1649.

23. Hoda SA, Hoda RS, Merlin S, Shamonki J, Rivera M: Issues relating to lymphovascular invasion in breast carcinoma. Adv Anat Pathol 2006, 13:308-315

24. Gujam FJA, Going JJ, Edwards J, Mohammed ZM, MCMillan DC: The role of lymphatic and blood vessel invasion in predicting survival and methods of detection in patients with primary operable breast cancer. Critical Rev Oncol Hematol 2014, 89:231-241.

25. Hammond ME, Hayes DF, Dowsett M, Allred DC, Hagerty KL, Badve S, Fitzgibbons PL, Francis G, Goldstein NS, Hayes M, Hicks DG, Lester S, Love R, Mangu PB, McShane L, Miller K, Osborne CK, Paik S, Perlmutter J, Rhodes A, Sasano H, Schwartz JN, Sweep FCG, Taube S, Torlakovic EE, Valenstein P, Viale G, Visscher D, Wheeler T, Williams RB et al: American society of clinical oncology/college of American pathologists guideline recommendations for immunohistochemical testing of estrogen and progesterone receptors in breast cancer. J Clin Oncol 2010, 28:2784-2795.

26. Mohammed ZMA, Going JJ, MCMillan DC, Mallon E, Doughty JC, Edwards J: Comparison of visual and automated assessment of HER2 status and their impact on outcome in primary operable invasive ductal breast cancer. Histopathology 2012, 61:675-684.

27. Schoppmann SF, Bayer G, Aumayr K, Taucher S, Geleff S, Rudas M, Kubista E, Hausmaninger H, Samonigg H, Gnant M, Jakesz R, Horvat R: Prognostic value of lymphangiogenesis and lymphovascular invasion in invasive breast cancer. Ann Surg 2004, 240:306-312.

28. Yamauchi C, Hasebe T, Iwasaki M, Imoto S, Wada N, Fukayama M, Ochiai A: Accurate assessment of lymph vessel tumor emboli in invasive ductal carcinoma of the breast according to tumor areas, and their prognostic significance. Hum Pathol 2007, 38:247-259.

29. Kato T, Kameoka S, Kimura T, Nishikawa T, Kobayashi M: Blood vessel invasion as a predictor of long-term survival for Japanese patients with breast cancer. Breast Cancer Res Treat 2002, 73:1-12

30. Kato T, Kimura T, Miyakawa R, Fujii A, Yamamoto K, Kameoka S, Nishikawa T, Kasajima T: Clinicopathologic study associated with long-term survival in Japanese patients with node-negative breast cancer. Br J Cancer 2000, 82:404-411

31. Desmedt C, Haibe-Kains B, Wirapati P, Buyse M, Larsimont D, Bontempi G, Delorenzi M, Piccart M, Sotiriou C: Biological processes associated with breast cancer clinical outcome depend on the molecular subtypes. Clin Cancer Res 2008, 14:5158-5165.

32. Wirapati P, Sotiriou C, Kunkel S, Farmer P, Pradervand S, Haibe-Kains B, Desmedt C, Ignatiadis M, Sengstag T, Schutz F, Goldstein DR, Piccart M, Delorenzi M: Meta-analysis of gene expression profiles in breast cancer: toward a unified understanding of breast cancer subtyping and prognosis signatures. Breast Cancer Res 2008, 10:R65.

33. Fan $C$, Oh DS, Wessels $L$, Weigelt $B$, Nuyten DSA, Nobel AB, van't Veer $L$, Perou CM: Concordance among gene-expression-based predictors for breast cancer. N Engl J Med 2006, 355:560-569.

34. Lauria R, Perrone F, Carlomagno C, Delaurentiis M, Morabito A, Gallo C, Varriale E, Pettinato G, Panico L, Petrella G, Bianco AR, Deplacido S: The prognostic value of lymphatic and blood-vessel invasion in operable breast-cancer. Cancer 1995, 76:1772-1778.

35. Lee AK, Delellis RA, Silverman ML, Heatley GJ, Wolfe HJ: Prognostic significance of peritumoral lymphatic and blood vessel invasion in node-negative carcinoma of the breast. J Clinical Oncol Official J Am Soc Clinical Oncol 1990, 8:1457-1465.

36. Schoppmann SF, Birner P, Studer P, Breiteneder-Geleff S: Lymphatic microvesse density and lymphovascular invasion assessed by anti-podoplanin immunostaining in human breast cancer. Anticancer Res 2001, 21:2351-2355.

37. Kaiserling E: Immunohistochemical identification of lymph vessels with D2-40 in diagnostic pathology. Pathologe 2004, 25:362-373.

38. Arigami T, Natsugoe $S$, Uenosono $Y$, Arima $H$, Mataki $Y$, Ehi $K$, Yanagida $S$, Ishigami S, Hokita S, Aikou T: Lymphatic invasion using D2-40 monoclonal antibody and its relationship to lymph node micrometastasis in pNO gastric cancer. Br J Cancer 2005, 93:688-693.

39. Arnaout-Alkarain A, Kahn HJ, Narod SA, Sun PA, Marks AN: Significance of lymph vessel invasion identified by the endothelial lymphatic marker D2-40 in node negative breast cancer. Mod Pathol 2007, 20:183-191.

40. Rabban JT, Chen YY: D2-40 expression by breast myoepithelium: potential pitfalls in distinguishing intralymphatic carcinoma from in situ carcinoma. Hum Pathol 2008, 39:175-183.

41. Martin SA, Perez-Reyes N, Mendelsohn G: Angioinvasion in breast carcinoma. An immunohistochem VIII-Related Antigen Cancer 1987, 59:1918-1922.

42. Horak ER, Leek R, Klenk N, Lejeune S, Smith K, Stuart N, Greenall M, Stepniewska K Harris AL: Angiogenesis, assessed by platelet endothelial-cell adhesion molecule antibodies, as indicator of node metastases and survival in breast-cancer. Lancet 1992, 340:1120-1124. 
43. Fox SB, Leek RD, Smith K, Hollyer J, Greenall M, Harris AL: Tumor angiogenesis in node-negative breast carcinomas - relationship with epidermal growth-factor receptor, estrogen-receptor, and survival. Breast Cancer Res Treat 1994, 29:109-116.

44. Gasparini G, Weidner N, Bevilacqua P, Maluta S, Dallapalma P, Caffo C, Barbareschi M, Boracchi P, Marubini E, Pozza F: Tumor microvessel density, P53 expression, tumor size, and peritumoral lymphatic vessel invasion are relevant prognostic markers in node-negative breast-carcinoma. J Clin Oncol 1994, 12:454-466.

doi:10.1186/1471-2407-14-676

Cite this article as: Gujam et al:: Immunohistochemical detection

improves the prognostic value of lymphatic and blood vessel invasion

in primary ductal breast cancer. BMC Cancer 2014 14:676.

\section{Submit your next manuscript to BioMed Central and take full advantage of:}

- Convenient online submission

- Thorough peer review

- No space constraints or color figure charges

- Immediate publication on acceptance

- Inclusion in PubMed, CAS, Scopus and Google Scholar

- Research which is freely available for redistribution 